\title{
THE FORMATION AND DEVELOPMENT OF THE CYLINDRICAL BODIES IN THE MAMMALIAN EPIDIDYMIS
}

\author{
J. MARTAN, Z. HRUBAN AND P. BROWN \\ Department of Zoology, Southern Illinois University, Carbondale, Illinois, and \\ Department of Pathology, University of Chicago, Chicago, Illinois
}

(Received 16th March 1971, revised 18th May 1971)

Recently, changes in cohesion of epididymal spermatozoa were reported in the flying squirrel (Martan \& Hruban, 1970), grey and fox squirrels (Martan, Adams \& Perkins, 1970), chinchilla (Martan, 1970a) and several other mammals, including primates (Martan, 1970b). Formations in which spermatozoa adhered tightly together by their tails or tails and heads were called cylindrical bodies. This article presents some additional observations and speculations on the formation and development of cylindrical bodies. The materials and methods involved have already been described in the above mentioned articles.

Stereocilia of principal cells protruding into the epididymal duct substantially reduce the size of the lumen. The proximal portion of the ductus epididymidis may therefore be regarded as having two lumina which differ considerably in diameter; a lumen limited by the apical parts of the epithelial cells and a reduced lumen (Reid \& Cleland, 1957) bordered by the tips of the stereocilia (Pl. 1, Figs. 1 to 4). Risley (1963) states that spermatozoa are propelled along the epididymal canal by smooth muscle contractions which cause movement of the fluid inside the lumen towards the distal portion of the duct. While the fluid can flow through the lumen proper, movement of the spermatozoa is restricted by the stereocilia to the reduced lumen (PI. 1, Figs. 1 to 4). The flow of spermatozoa through the reduced lumen may help to orientate them along their long axis and concentrate them into closer promixity so that, through cohesion of their tails, the formation of cylindrical bodies begins (Pl. 1, Fig. 2).

The length of the ductus epididymidis travelled by spermatozoa in these closely formed cylindrical bodies and the epididymal segment in which cylindrical formations first appear differ according to species (Martan, 1970b). However, all cylindrical bodies once formed seem to grow in diameter (Pl. 1, Figs. 2 to 4 ) and in length (Pl. 1, Figs. 5 and 6 ) before they break up. We propose that, in order to grow in both directions, additional spermatozoa must adhere to the already formed cylindrical body. These spermatozoa, which are released later from the testis than those already in the epididymidis, catch up with the freshly built cylindrical body somewhere in the proximal part of the duct. As the cylindrical formation is propelled by smooth muscle contractions along the reduced lumen of the epididymal duct, the stereocilia could exert a dragging 
effect on its surface, thus slowing it down (Pl. 1, Figs. 1, 3 and 4). Epididymal fluid flows between the stereocilia, leaving additional spermatozoa in the reduced lumen. Growth in the length of the cylindrical body (Pl. 1, Fig. 6) could be caused by adhesion of these spermatozoa to the already formed structure.

The spermatozoa in the cylindrical bodies of all mammals so far investigated were observed to be adhering together by their tails and were orientated with their long axes parallel to the long axis of the cylindrical body (Martan, 1970b). Only the spermatozoa in the cylindrical formations of the flying squirrel (Martan \& Hruban, 1970), fox and grey squirrels (Martan et al., 1970), chipmunk and thirteen-lined ground squirrel, Tamias striatus, Citellus tridecemlineatus, (unpublished observation) showed perfect polarity (Pl. 1, Figs. 5 and 6). When these polar cylindrical bodies were followed in consecutive sections of the flying squirrel epididymis, they seemed to pass caudally with the sperm heads first.

In the above mentioned species and in the guinea-pig, the cohesion of sperm tails was followed by cohesion of sperm heads. Head cohesion in Sciuridae occurs in the cylindrical bodies and for a while, spermatozoa adhere together along their whole length before the cylindrical bodies break up (Martan \& Hruban, 1970; Martan et al., 1970; Martan, 1970b).

Guinea-pig spermatozoa adhering by their heads form rouleaux (Fawcett \& Hollenberg, 1963). In all other animals so far investigated, cohesion of sperm tails only was observed in the cylindrical bodies (Martan, 1970b). Because these bodies form at different levels of the epididymal duct, according to the species involved, and in some species they even form in the distal part of ductuli efferentes (Martan, 1970b), it is probable that change in the cohesiveness of the sperm tail is an intrinsic property of the mammalian spermatozoon.

In the polar cylindrical bodies of Sciuridae, where the cohesive properties of the spermatozoa spread from the tail to involve the whole sperm cell (Martan \& Hruban, 1970; Martan et al., 1970), the intimate relationship between epithelial cells and sperm heads suggest some epididymal influence. Cytoplasmic ribose nucleic acid has been observed in the epithelium of the proximal part of the epididymal duct in all members of family Sciuridae so far investigated. The peculiar apical concentration of this cytoplasmic RNA also infers some epididymal rôle in the formation of polar cylindrical bodies (Martan \& Hruban, 1970; Martan et al., 1970). A possibility exists that the unusually large, cupshaped sperm heads of Sciuridae adapt themselves easily to some surface-tosurface interaction without any epididymal intervention but the regular spacing of the sperm heads on the periphery of the polar cylindrical body suggests some epididymal influence.

The nature of the cohesive properties which are probably confined to the sperm cell membrane and which keep spermatozoa in the cylindrical bodies is not known. In all the mammals investigated, the strength of the cohesion diminished as the spermatozoa passed down the epididymal duct, the cylindrical bodies gradually breaking down into disorganized masses of individual spermatozoa (Martan, 1970b). The only exception was the guinea-pig in which tail cohesion in the cylindrical bodies was replaced by head cohesion in rouleaux.

The close association between spermatozoa forming the cylindrical body may 
PLATE 1
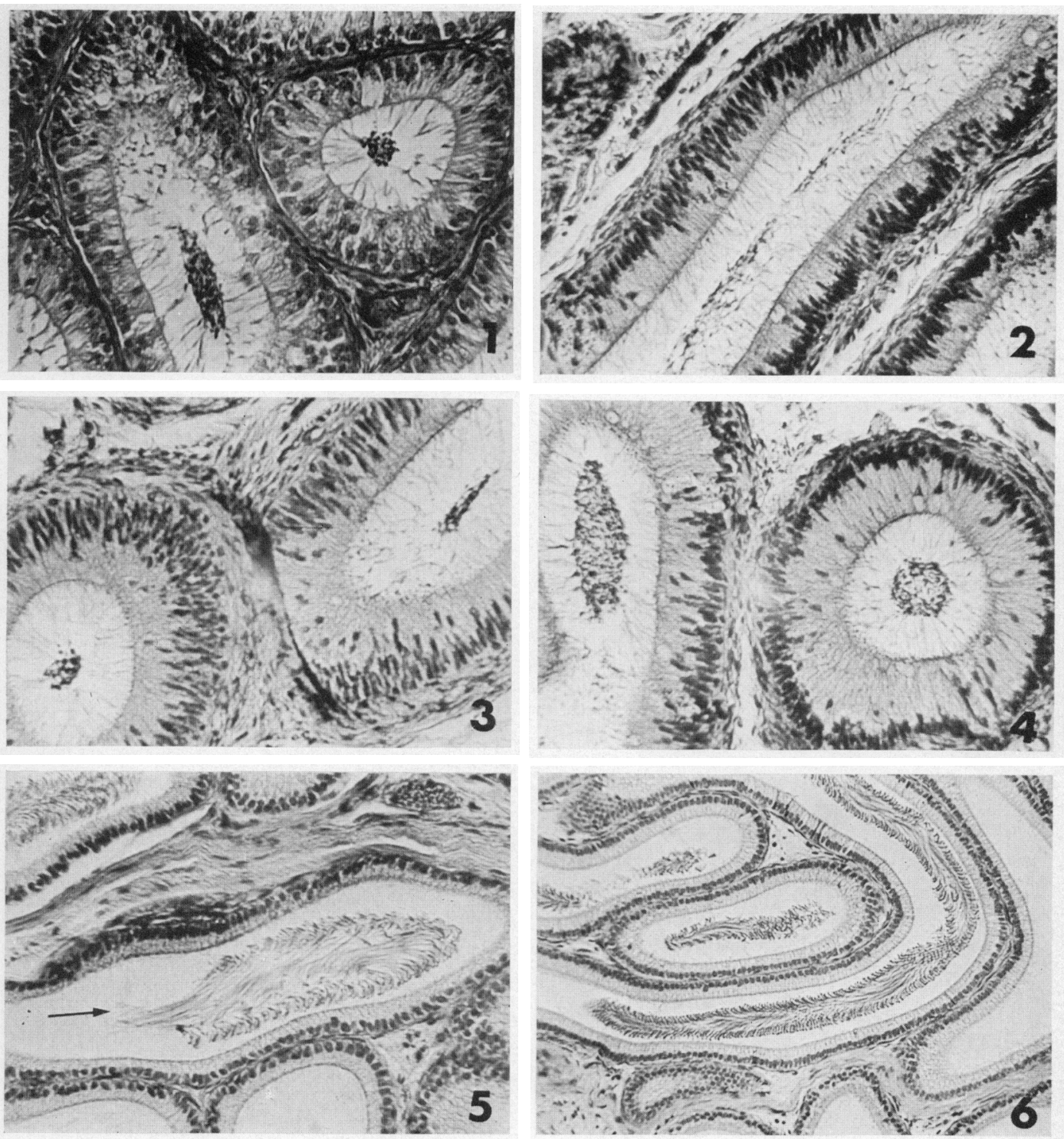

All tissues fixed in $10 \%$ formalin, $1 \%$ cadmium chloride.

FIG. 1. Initial segment of the epididymis of hedgchog, Erinaceus europeus. Longitudinal section and cross section through cylindrical body. Note reduction of epididymal lumen by stereocilia. PAS-haematoxylin, $\times 170$.

FIG. 2. Initial segment of the epididymis of howler monkey, Alouatta palliata. Spermatozoa starting to form cylindrical body in the reduced lumen of the epididymal duct. Haematoxylin-eosin, $\times 170$.

Figs. 3 and 4. Same segment, same species as in Fig. 2. Notice the stereocilia extending to the surface of enlarged cylindrical bodies. Haematoxylin-eosin, $\times 170$.

Fig. 5. Segment 2 of the epididymis of flying squirrel, Glaucomys volans. Arrow indicates the orientation of polarized cylindrical body toward the distal portion of epididymis. Haematoxylin-eosin, $\times 170$.

FIG. 6. Same segment, same species as in Fig. 5. Unusually long longitudinal section through the polarized cylindrical body. Haematoxylin-eosin, $\times 105$.

(Faring p. 116) 
be necessary for their maturation. In polar cylindrical bodies, every sperm cell has an identical environment (Pl. 1, Figs. 5 and 6). This may assist close coordination of their maturation with or without any epididymal influence. The synchronized position and movement of the sperm cytoplasmic droplet in the polar cylindrical bodies of Sciuridae (Martan \& Hruban, 1970; Martan et al., 1970) supports this explanation.

In non-polar cylindrical bodies, where spermatozoa are located on the periphery or in the centre of the body (Martan, 1970b), the environment presumably varies for individual spermatozoa (Pl. 1, Figs. 1 and 4). The maturation process then will not be closely synchronized and spermatozoa in a different degree of maturation will be found in the distal portion of the epididymis. Additional experiments will be needed to show that these predictions are correct.

\section{REFERENCES}

FAwCETt, D. S. \& Hollenserg, R. D. (1963) Changes in the acrosome of guinea pig spermatozoa during passage through the epididymis. Z. Zellforsch. mikrosk. Anat. 60, 276.

Martan, J. (1970a) Epididymal spermatozoa in chinchilla. (Abstract). Anat. Rec. 166, 345.

MARTAN, J. (1970b) Cohesive properties of mammalian epididymal spermatozoa. F. Morph. 132, 389.

Martan, J., Adams, C. S., \& Perkins, B. L. (1970) Epididymal spermatozoa of two species of squirrels. 7. Mammal. 51, 376.

Martan, J. \& Hruban, Z. (1970) Unusual spermatozoan formations in the epididymis of the flying squirrel (Glaucomys volans). F. Reprod. Fert. 21, 167.

ReID, B. L. \& Gleland, K. W. (1957) The structure and function of the epididymis. Aust. F. Zool. 5, 223.

Risley, P. L. (1963) Physiology of the male accessory organs. In: Mechanisms Concerned with Conception. Ed. C. G. Hartman. Pergamon Press, New York. 